\title{
Problems and perspectives in weed management
}

\author{
Donato Loddo, ${ }^{1}$ J. Scott McElroy, ${ }^{2}$ Vittoria Giannini ${ }^{3}$ \\ ${ }^{1}$ Institute for Sustainable Plant Protection, National Research Council of Italy, Legnaro (PD), Italy; \\ ${ }^{2}$ Department of Crop, Soil, and Environmental Sciences, Auburn University, Auburn, AL, USA; \\ ${ }^{3}$ Department of Agricultural Sciences, University of Sassari, Sassari, Italy
}

\begin{abstract}
Highlights
- Herbicides availability is being reduced by the evolution of herbicide resistance.

- The registration of new active ingredients got more complicated with stricter regulatory restrictions.

- Innovative non-chemical tactics and tools are being developed.

- Not all the alternative weed tools and tactics have the same readiness and marketability.

- A new paradigm implies reducing herbicide inputs and integrating innovative tools and tactics.
\end{abstract}

\begin{abstract}
Despite the wide use of herbicides in the past century, their use is decreasing due to rising resistance phenomena, the absence of discovery of new modes of action, and more regulatory restrictions. On the other hand, several tactics and technologies have been developed recently, providing alternatives from mechanical, cultural, robotic, and natural product use perspectives that could profitably enhance weed management within the agroecosystem and usher in a new paradigm of weed management that integrates chemical and non-chemical weed management practices.

In the next future, herbicides will remain an important tool for weed management and will be increasingly complemented by other innovative tactics and tools from an integrated weed man-
\end{abstract}

Correspondence: Vittoria Giannini, Department of Agricultural Sciences, University of Sassari, viale Italia 39A, 07100 Sassari, Italy. E-mail: vgiannini@uniss.it

Key words: Herbicides; cultural management; precision spraying; robotic weeding; natural chemicals; integrated weed management.

Acknowledgements: Dr. Giannini was supported by Programma Operativo Nazionale (PON) Ricerca e Innovazione 2014-2020 (Linea 2- Attrazione dei Ricercatori, AIM1853149-1, CUP: J54118000120001). For Dr. McElroy's contribution, this publication was supported by the Alabama Agricultural Experiment Station and the Hatch Program of the National Institute of Food and Agriculture, U.S. Department of Agriculture.

Received for publication: 26 February 2021.

Accepted for publication: 22 May 2021.

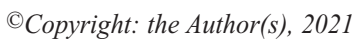

Licensee PAGEPress, Italy

Italian Journal of Agronomy 2021; 16:1854

doi:10.4081/ija.2021.1854

This article is distributed under the terms of the Creative Commons Attribution Noncommercial License (by-nc 4.0) which permits any noncommercial use, distribution, and reproduction in any medium, provided the original author(s) and source are credited. agement perspective. This integrated approach would thus preserve the chemical and transgenic technology for future generations.

\section{Introduction}

Chemical weed control through the utilization of herbicides is the primary form of weed management in modern agriculture worldwide. Since their progressive introduction in the 1940-50s, synthetic carbon-based herbicides have significantly contributed to more efficient weed control, allowing a reduction of frequency and intensity of soil tillage operations and labour demand for weeding (Gianessi and Reigner, 2007; Gianessi, 2013). The availability of effective herbicides, particularly after the diffusion of herbicide-resistant transgenic crops, has facilitated the adoption of no-till agriculture practices across millions of hectares of cultivated land in North and South America, reducing soil erosion and capturing more carbon from the atmosphere to be stored in the soil (Bonny, 2008; Cerdeira et al., 2011; Duke, 2015). Given their efficacy as weed control tools, herbicides are the second most used group of pesticides, after fungicides in Europe. In EU-27, over the 2015-2019 period, herbicide sales reached an average of 130,000 tonnes per year, while fungicides and insecticides accounted for 160,000 and 40,000 tonnes per year, respectively (EUROSTAT, 2020).

Despite the pivotal role played in modern agriculture over the past 80 years, sustainable herbicide use is under threat in three ways. First, herbicide resistance is evolving worldwide, reducing the number of herbicide active ingredients available for use. Second, herbicide development has slowed with few if any new modes of action introduced in recent years. While herbicide resistance has been occurring for decades, the lack of new modes of action exacerbates the problem of herbicide resistance. Third, there is a change in public sentiment concerning herbicide use around the world, some of which can be attributed to an excessive perception of herbicide risks compared to the actual ones, which has led Europe to stricter regulation in herbicide use. In this manuscript, we will discuss these three processes and the realities of the development of new weed management technologies and tactics that could complement chemical-based weed management, thus preserving valuable herbicide technology. 


\section{Herbicide resistance}

The evolution of herbicide resistance is progressively reducing the number of effective herbicides available for farmers. According to updated surveys, 521 unique cases of herbicide resistance have been recorded so far involving all the most used herbicides: 166 cases regarding resistance to Acetolactate Synthase inhibitors, 74 cases regarding triazines, 53 regarding glycines, and 49 involving acetyl-CoA carboxylase inhibitors (ACCaseinhibitors) (Heap, 2021). Herbicide resistance strongly affects weed management, particularly after the spread of weeds with multiple resistance to herbicides with different modes of action (MOAs). For example, in wheat-growing areas in Europe, the widespread presence of ACCase-inhibitors resistant grass weeds, such as Lolium spp., has forced farmers to replace the once-predominant herbicides with acetolactate synthase inhibitors (ALSinhibitors). However, after a few years of reliance on these latter herbicides, resistance has also evolved against ALS-inhibitors, and weeds with multiple resistance are now common (Loureiro et al., 2017; Scarabel et al., 2020; Torra et al., 2021). Farmers then adopt other classes of herbicides to support or replace those that have reduced efficacy due to the evolution of herbicide resistance, entering into a continuous process of new herbicide use or combining new herbicides that can be referred to as a 'herbicide treadmill' following the concept of the 'pesticide treadmill' (Foster and Magdoff, 2000).

Similar processes have occurred in many cropping systems worldwide, including also genetically modified organisms (GMO) cropping systems where the evolution of glyphosate and glufosinate resistance has made the first herbicide-tolerant varieties less effective against all weeds, necessitating that farmers use other herbicide MOAs in addition to glyphosate and glufosinate (Beckie, 2011). This has led to the introduction of novel GMO varieties with stacked herbicide-tolerant traits able to tolerate a broader spectrum of MOAs, such as dicamba and carotenoid biosynthesis resistant crop varieties which have prompted herbicide use changes again but also promoted the further evolution of resistance against these additional MOAs (Beckie and Hall, 2014; Bonny, 2016), constituting a new process of intensification, the 'transgenic or transgene-facilitated treadmill' (Binimelis et al., 2009; Mortensen et al., 2012). Weeds will adapt to any anthropogenic activity, including herbicides (McElroy, 2014), once they are subjected to repeated and constant disturbances provoking selection pressure. Utilization of herbicides along with non-herbicide weed management practices could have prevented or at least delayed resistance evolution thus, preserving valuable herbicide and transgenic technology.

\section{Herbicide research and development}

The slowdown of herbicide discovery worsens the loss of spectrum of herbicide effectiveness. No new herbicide sites of action (SOA) has been developed in the last decades (Duke, 2012), and only recently research activity and resource allocation in the herbicide discovery sector has increased, leading to the identification in 2018 of three herbicides possessing new modes of action (Umetsu and Shirai, 2020): cyclopyrimorate (site of action HTS, homogentisate solanesyl transferase, a downstream enzyme of HPPD) has been recently launched in Japan, tetflupyrolimet (site of action $\mathrm{DHODH}$, dihydroorotate dehydrogenase, an enzyme connected with de novo pyrimidine biosynthesis) is currently under development, and cinmethylin (site of action FTA, fatty acid thioesterase, leading to the inhibition of fatty acid biosynthesis) has been approved in Australia. Nevertheless, no new herbicides with innovative SOAs will be commercialized in the next few years in most countries in the world (Kraehmer et al., 2014; Dayan, 2019).

The investments required to discover, develop and meet regulatory requirements for a new active ingredient have been progressively increasing (Bomgardner, 2011), representing, therefore, a strong deterrent for many companies to develop new chemical technology. More chemical compounds must be tested and evaluated to discover new and effective active ingredients than in the past since the most easy-to-find herbicide SOAs have already been discovered and fully exploited. Furthermore, more complex and costly toxicological and environmental studies are required to comply with the increasingly stricter requirements for registering a new active ingredient, particularly in the EU (Peters and Strek, 2008; Kraehmer et al., 2014). As a consequence, companies have preferred to develop and register new formulations or mixtures of old active ingredients, whose control efficacy and toxicity profile are easily predictable, instead of investing money in discovering new chemical classes of herbicides with new SOAs (Duke, 2012). Meanwhile, the rapid diffusion of GMO herbicide-tolerant crops in North and South America and Australia has contributed to limit for the last two decades the demand for new herbicides. Many farmers, who had previously used a range of diversified herbicides after adopting GMO crops, started relying almost exclusively on glyphosate (Bonny, 2008; Wilson et al., 2011). This caused a relevant reduction in the use of other herbicides in the main field crops (Nelson and Bullock, 2003).

\section{Pesticide regulation}

Pesticides are regulated by governmental agencies to evaluate their potential benefits and hazards and to aid in providing documentation on how to use pesticide products safely and effectively once registered. To illustrate how the different countries assess pesticides, we will compare the United States to the European Union.

\section{United States}

The Environmental Protection Agency is the regulatory body charged with registering and regulating pesticide usage in the United States under the authority of the Federal Insecticide, Fungicide, and Rodenticide Act (FIFRA). The United States Environmental Protection Agency (USEPA) uses a risk assessment process to evaluate pesticides in the regulatory process (USEPA, 2021). Risk is the potentially harmful effect of a pesticide for nontarget organisms and the environment associated with a given level of exposure that derives from its use under given technical and environmental conditions. All chemicals have potential risks associated with their use that must be quantified in the regulatory process and mitigated in pesticide labelling. Harm from possible risks can be reduced by using mitigation strategies to minimize human and environmental exposure. The USEPA also conducts re-registration reviews of pesticides that take in new data, as well as a public comment to provide a continual assessment of pesticide safety.

\section{European Union}

The concern and awareness of alleged health risks and environmental impacts of pesticide use have increased in European 
public opinion. The European Union, therefore, acknowledged there is public demand for agriculture with lower pesticide use with the introduction of Regulation (EC) No 1107/2009 'concerning the placing of plant protection products on the market.' A twostep procedure has been adopted to approve new active ingredients or the renewal of already-used active ingredients.

Firstly, a hazard-based assessment is conducted. Differently from the risk-assessment procedure, hazard-based assessment of a pesticide considers only its intrinsic toxicity, that is, the type and nature of adverse effects it may cause in an organism, without estimating the degree of exposure of that organism to the pesticide under conditions of field application. According to some 'cut-off' criteria, all pesticides containing substances considered of high concern for human health (e.g., carcinogens cat 1A, 1B) or the environment (e.g., persistent organic pollutants, POP) are removed from the market. Once active ingredients are not discarded by the hazard-assessment, they are evaluated with a risk-assessment procedure to verify that they have, 'consequent on application consistent with good plant protection practice and having regard to realistic conditions of use,' no harmful or unacceptable effects on human health, animal health, and the environment. The rationale behind Regulation (EC) 1107/2009 is to replace the old, more toxic active substances with newer and safer active substances or with non-chemical control methods. However, this has significantly reduced the availability of active substances for plant protection, with an estimated loss of at least $20 \%$ of active substances in the first years after the introduction of this Regulation and important effects on crop management since farmers can rely on fewer active ingredients, with the consequent greater risk of evolution of herbicide resistance if alternative non-chemical weed control tactics will not be adopted (Hillocks, 2012; Jess et al., 2014).

\section{The future of weed management}

Regardless of the reasons, agriculture could largely be living in or have recently lived through a period of 'peak herbicide' - a point of maximum herbicide usage for weed management. The constraints of herbicide resistance, lack of new herbicide development, and greater regulatory scrutiny could continue to erode the use of herbicides, as well as other pesticides. Herbicides have revolutionized weed management, allowing humanity to grow more food and fibre on less land with less labour, and will continue to be the primary mechanism of weed management in the future, particularly for some cropping systems. However, a herbicides-dependent model requires a new paradigm for integrated weed management within agroecosystems to preserve herbicide technology and complement their efficacy.

An integrated weed management approach has been proposed for decades as a means of more sustainable weed management (see Barzman et al., 2015; Liebman et al., 2016) that will also aid in the preservation of valuable herbicide and transgenic technology. What makes 'today' different is simply that there is no longer a choice. With fewer herbicide active ingredients as described, farmers must utilize integrated practices to supplement or even substitute the use of herbicides. In the remainder, we will discuss some of the most promising innovative tactics and technologies that could contribute to designing integrated weed management practices that could complement herbicide use. Many of these new technologies are in their infancy, and their long-term impacts have not been realized. None of these practices are thought to be per se a definitive replacement for herbicides in the future but will func- tion as a supplement or periodic alternative in integrated weed management scenarios.

\section{Reducing broadcast applications}

Herbicides are traditionally applied broadcast on the whole field surface, even on areas where they are not strictly necessary because no weeds are present or because other control methods are applied, as in the case of the inter-row of wide rows crops where mechanical weed control can be performed in addition to herbicide application. Different systems have been developed to reduce herbicide use by limiting their application only to field areas where weeds are present. Systems based on the combination of herbicide band application along the crop row and mechanical control in the inter-row have been proposed for different wide row crops, obtaining satisfactory weed control and crop yields with relevant reduction of herbicide use (Main et al., 2013; Pannacci and Tei, 2014; Vasileiadis et al., 2016). Further advances in the band application accuracy have become achievable with the diffusion of real-time kinematic global positioning system (RTK-GPS) and auto-steering systems for the tractors and camera-guided row-centring systems for the sprayers (Perez-Ruiz et al., 2013; Loddo et al., 2020). Similarly, ultra-high precision spraying systems have been developed with the integration of RTK-GPS positioning technologies, accurate cameras and optical sensors, image analysis and computer vision software, machine learning, and very precise robotic nozzles. These systems, able to identify and distinguish single weed and crop plants and then apply herbicides only on weed plants, have been used by different companies to create ultra-precise mounted sprayers (www.bluerivertechnology.com) but also autonomous, solar-powered robots (www.ecorobotix.com/en). Thanks to this extremely accurate targeted application, these systems are believed to reduce herbicide use up to $90-95 \%$ compared to broadcast application; however, this efficiency can be achieved only in fields with low to moderate weed density. Therefore, these systems should be considered an integration of other control tactics (chemical, cultural, mechanical); conversely, it is not recommended to base the entire weed management solely on these systems.

Besides, some weed species will likely evolve to mimic the appearance of desirable crops to thwart sensor technology as already occurred against other control tactics based on crop-weed discrimination. For example, Echinochloa crus-galli evolved to resemble cultivated rice due to human hand-weeding selection pressure resulting in the evolution of the E. crus-galli ssp. oryzicola subspecies (McElroy, 2014). If species can evolve to confuse human eyes, weeds can evolve to confuse sensor technology.

\section{Mechanical and physical weed management}

From a mechanical perspective, the recent development of auto-steering types of machinery, equipped with optical sensors and RTK-GPS technologies to identify crop rows and hydraulic systems for real-time adjustment of tool positions, can improve weed control efficacy, reduce crop damage, and significantly increase working speed and capacity in different wide row crops (Kunz et al., 2018; Gerhards et al., 2020; Spaeth et al., 2020). Besides the low-tech mechanical devices such as cultivators, finger-weeders, brush weeders, and torsion weeders used in low-density crops (Peruzzi et al., 2017), a series of alternatives have been presented by machines using heat for weed control both in preemergence and post-emergence phases. Indeed, soil steaming has proved to be a promising pre-emergence strategy killing most weed seeds, including dormant seeds (Kim et al., 2021); while in post-emergence, heat could be used to control weeds through flam- 
ing (Rajković et al., 2021) and microwave technologies (Khan et al., 2018), whose effectiveness is based on plant susceptibility to high temperatures determining the interruption of many biological and physiological processes. In addition to those technologies, cryogenic weed control has also been tested with promising effects (Cutulle et al., 2013). Moreover, as a response to the increasing diffusion of herbicide-resistant weeds, different systems have been developed to destroy weed seeds during crop harvest (harvest weed seed control). These systems, now commonly adopted in Australia, have shown promising potentials in reducing populations of important weed species, such as Amaranthus palmeri S. Wats., Amaranthus tuberculatus (Moq.) J.D. Sauer, Chenopodium album L., Kochia scoparia (L.) Schrad. or Lolium rigidum Gaud., across different cropping systems worldwide (Walsh et al., 2018; Shergill et al., 2020).

Increased mechanical activity in agricultural fields will have unintended consequences such as increased soil compaction due to increased entry of heavy mechanical equipment and increased burning of fossil fuels to power additional mechanical equipment. Therefore, mechanical weed management will not be a solution in all crops, only those crops that can be grown with specific row spacing and planting timings. Moreover, weed populations could shift to more perennial vegetation that is more difficult to physically remove or potentially damages desirable plants when removed (Fried et al., 2012).

Steaming, burning, microwave, and cryogenic practices will also be limited to specific crops that are more tolerant to possible damage from such practices. Human safety will also be a major hurdle to the use of these practices, as accidental exposure could be deadly to the applicator.

\section{Robotic weed management}

More recently, a new generation of robotic and automatic machines has provided not only quick weed identification in fields but also weed-targeted intervention (Steward et al., 2019), with possible further update strategies able to fasten timing in weed emergence annotation and prompt management strategy, for example using a fleet of unmanned aerial vehicles and unmanned ground vehicles with complementary functions (Gonzalez de Santos et al., 2017) and thus exploiting both grounds detected and remotely sensed data. In addition, autonomous weeding robots based on GPS/RTK technologies, such as Dino by Naïo-technologies (www.naio-technologies.com) or Robotti by Agrointelli (www.agrointelli.com), are already available on the market.

Robotic weed management is likely years if not decades away from broad commercialization and adoption, especially for largescale field crops. Furthermore, there is still uncertainty about the economic benefits related to the introduction of weeding robots, considering both the initial investment and upkeep costs of robotic technology. In addition, such technology will require a new skill set for farmers to service and maintain fleets of robot weeders.

\section{Cultural management}

From the agronomic perspective, over the well-known strategies concerning the selection of competitive cultivars, the optimization of seed density, and fertilizers, several others crucially characterize the agroecosystem design and are driving much attention. Among these latter, row configuration, the distance between consecutive rows and management of inter-rows with living or mulching, relay intercropping can interplay with weeds for light, nutrients, and water availability (De Vita et al., 2017; Carlesi et al., 2020). Underneath the agroecosystem design, the inter-row crop- ping with plants able to produce allelochemicals can represent a strengthening tactic to suppress weeds (Jabran, 2017) as well as planning cover crops within the cropping system rotation, which have demonstrated to furnish several ecosystem services (Adeux et al., 2021; Silvestri et al., 2021) especially when they are not intended as monocultures but as mixtures of different species (Ranaldo et al., 2020; Hefner et al., 2020). Recent studies have also underlined the importance of choosing, according to local agronomic and environmental conditions, the appropriate techniques for cover crop termination, such as chemical termination, roller-crimper or soil incorporation, to maximize weed suppression and beneficial effect on the following cash crops (Navarro-Miró et al., 2019; Frasconi et al., 2019; Alonso-Ayuso et al., 2020). Cover crops have been clearly demonstrated to reduce weed populations but not completely eliminate all weeds; thus, necessitating additional weed management practices such as herbicides.

\section{Natural chemicals}

Interest has been rising in essential oils, obtained by hydrodistillation or steam distillation from aromatic plants' organs (Shaaban et al., 2012), that are mainly constituted by terpene hydrocarbons (monoterpenes and sesquiterpenes) or oxygenated compounds (phenols, alcohols, aldehydes, and esters) and that have proved to have a 'burning' and thus 'non-specific' transient effect on many weeds (Jouini et al., 2020; Pouresmaeil et al., 2020). However, given their high volatility, which could limit their fruitful use, especially in organic farming, and their actual short shelf-life, promising attempts for their encapsulation with natural polymers such as Arabic gum, starch, alginate, and pectin are being tested. Indeed, safe nanotechnologies could enhance essential oils' release properties and activities against unwanted organisms (Vurro et al., 2019; Taban et al., 2020), giving those products marketability that they do not yet have.

From the bio-based side, the exploration of natural resources to identify new active bio compounds is proceeding lively, with a particular focus on secondary metabolites. In this regard, some coproducts of industrial vegetable oil production for bioenergy and green chemistry, such as defatted Brassicaceae seed meal derived from seed defatting procedures and containing high levels of glucosinolates, have shown suppressive effects against weeds (D'Avino et al., 2015; Matteo et al., 2018). To the big category of the bio-based products with herbicidal effects belong the fatty acids able to control a broad-spectrum of weeds and exhaustively represented by pelargonic acid, which is currently integrated into different marketed bioherbicides (Cordeau et al., 2016).

Given their herbicidal action only by contact, their use should be directed to the early weed seedling stage. Conversely, natural chemicals largely provide only temporary control of large annual or perennial weeds, thus necessitating multiple applications for acceptable control. In addition, natural chemicals are largely nonselective in their herbicidal effect, so desirable plants can be easily injured (Dayan et al., 2011). Selectivity towards crops could be achieved through localized applications, thus avoiding the crop plants. Although natural, those products could present some hazards for the operators; thus risks related to their application should be taken into account.

\section{Final thoughts: a new paradigm}

In recent years, a series of tactics and tools belonging to mechanical, agronomic, and bio-based approaches have been studied, offering the possibility of developing case-specific integrated weed man- 
agement (IWM) strategies with a cumulative impact on weed abundance and weed-competitive ability (Korres et al., 2019). In addition, IWM can rely on modern technologies, remotely sensed data, and robotics to control weeds (Lopez-Granados, 2011; Fennimore and Cutulle, 2019). As a result, IWM now has a diverse suite of tools and strategies that can be used to complement herbicides. Two decades ago, non-herbicide strategies for IWM were limited mainly to cultural and mechanical practices. Moreover, farmers must consider the current political and regulatory scenarios affecting the range of available tools and tactics for weed management. For example, the European Commission is increasingly asking for a consistent reduction of pesticide use, as stated by the 'Farm to Fork' strategy that imposes to reduce pesticide use by $50 \%$ by 2030 (European Commission, 2021). Regardless of the weed management strategy used in the future, a new paradigm for weed management is on the horizon. This new paradigm will be one of the reduced herbicide inputs and integration of non-herbicide management practices. Herbicides have been revolutionary tools, and their total replacement by alternative weed management strategies would not be feasible in the near future. However, the combination of herbicides and alternative management practices will aid in designing more sustainable cropping systems and preserving valuable herbicides and transgenic technology.

\section{References}

Adeux G, Cordeau S, Antichi D, Carlesi S, Mazzoncini M, Munier-Jolain N, Bàrberi, P, 2021. Cover crops promote crop productivity but do not enhance weed management in tillagebased cropping systems. Eur. J. Agron. 123:126221.

Alonso-Ayuso M, Gabriel JL, Hontoria C, Ibáñez MÁ, Quemada M, 2020. The cover crop termination choice to designing sustainable cropping systems. Eur. J. Agron. 114:126000.

Barzman M, Bàrberi P, Birch ANE, Boonekamp P, DachbrodtSaaydeh S, Graf B, Hommel B, Jensen JE, Kiss J, Kudsk P, Lamichhane JR, Messéan A, Moonen A-C, Ratnadass A, Ricci P, Sarah J-L, Sattin M, 2015. Eight principles of integrated pest management. Agron. Sustain. Dev. 35:1199-215.

Beckie HJ, 2011. Herbicide-resistant weed management: Focus on glyphosate. Pest Manag. Sci. 67:1037-48.

Beckie HJ, Hall LM, 2014. Genetically-modified herbicide-resistant (GMHR) crops a two-edged sword? An Americas perspective on development and effect on weed management. Crop Prot. 66:40-5.

Binimelis R, Pengue W, Monterroso I, 2009. 'Transgenic treadmill': Responses to the emergence and spread of glyphosateresistant johnsongrass in Argentina. Geoforum 40:623-33.

Bonny S, 2008. Genetically modified glyphosate-tolerant soybean in the USA: Adoption factors, impacts and prospects. A review. Agron. Sustain. Dev. 28:21-32.

Bonny S, 2016. Genetically modified herbicide-tolerant crops, weeds, and herbicides: overview and impact. Environ. Manage. 57:31-48.

Bomgardner MM, 2011. Germinating pesticides. Chem. Eng. News 89:13-7.

Carlesi S, Bigongiali F, Antichi D, Ciaccia C, Tittarelli F, Canali S, Bàrberi $\mathrm{P}, 2020$. Green manure and phosphorus fertilization affect weed community composition and crop/weed competition in organic maize. Renew. Agric. Food Syst. 35:493-502.

Cerdeira AL, Gazziero DLP, Duke SO, Matallo MB, 2011. Agricultural impacts of glyphosate-resistant soybean cultiva- tion in South America. J. Agric. Food Chem. 59:5799-807.

Cordeau S, Triolet M, Wayman S, Steinberg C, Guillemin JP, 2016. Bioherbicides: Dead in the water? A review of the existing products for integrated weed management. Crop Prot. 87:44-9.

Cutulle MA, Arme GR, Brosnan JT, Kopsell DA, Hart WE, Vargas JJ, Gibson LA, Messer RE, McLemore AJ, Duncan HA, 2013. Evaluation of a cryogenic sprayer using liquid nitrogen and a ballasted roller for weed control. J. Test. Eval. 41:869-74.

D'Avino L, Matteo R, Malaguti L, Pagnotta E, Righetti L, Ugolini L, Lazzeri L, 2015. Synergistic inhibition of the seed germination by crude glycerin and defatted oilseed meals. Ind. Crops Prod. 75:8-14.

De Vita P, Colecchia S A, Pecorella I, Saia S, 2017. Reduced interrow distance improves yield and competition against weeds in a semi-dwarf durum wheat variety. Eur. J. Agron. 85:69-77.

Dayan FE, Howell JL, Marais JP, Ferreira D, Koivunen M, 2011. Manuka oil, a natural herbicide with pre-emergence activity. Weed Science 59:464-9.

Dayan FE, 2019. Current status and future prospects in herbicide discovery. Plants 8:341.

Duke SO, 2012. Why have no new herbicide modes of action appeared in recent years? Pest Manag. Sci. 68:505-12.

Duke SO, 2015. Perspectives on transgenic, herbicide-resistant crops in the United States almost 20 years after introduction. Pest Manag. Sci. 71:652-7.

European Commission, 2020. Communication from the Commission to the European Parliament, the Council, the European Economic and Social Committee and the Committee of the Regions A Farm to Fork Strategy for a fair, healthy and environmentally-friendly food system COM/2020/381 final. Available from: https://eur-lex.europa.eu/legalcontent/EN/TXT/?uri=CELEX:52020DC0381 Accessed: 26 April 2021.

EUROSTAT, 2020. Agri-environmental indicator - consumption of pesticides. Available from: https://ec.europa.eu/eurostat/statistics-explained/index.php/Agri-environmental_indicator__consumption_of_pesticides Accessed: 01 April 2021.

Fennimore SA, Cutulle M, 2019. Robotic weeders can improve weed control options for specialty crops. Pest Manag. Sci. 75:1767-74

Foster JB, Magdoff F, 2000. Liebig, Marx, and the depletion of soil fertility: relevance for today's agriculture. In: F. Magdoff, J.B. Foster, \& F. Buttel (Eds.), Hungry for profit. NYU Press, New York, NY, USA, pp. 43-60.

Frasconi C, Martelloni L, Antichi D, Raffaelli M, Fontanelli M, Peruzzi A, Benincasa P, Tosti G, 2019. Combining roller crimpers and flaming for the termination of cover crops in herbicide-free no-till cropping systems. PLoS One 14:e0211573.

Fried G, Kazakou E, Gaba S, 2012. Trajectories of weed communities explained by traits associated with species' response to management practices. Agric. Ecosyst. Environ. 158:147-55.

Gerhards R, Kollenda B, Machleb J, Möller K, Butz A, Reiser, D, Griegentrog H-W, 2020. Camera-guided weed hoeing in winter cereals with narrow row distance [Kamera-gesteuertes Hacken in Getreide mit engem Reihenabstand]. Gesunde Pflanz. 72:403-11.

Gianessi LP, Reigner NP, 2007. The value of herbicides in U.S. crop production. Weed Technol. 21:559-66.

Gianessi LP, 2013. The increasing importance of herbicides in worldwide crop production. Pest Manag. Sci. 69:1099-105.

Gonzalez-de-Santos P, Ribeiro A, Fernandez-Quintanilla C, Lopez-Granados F, Brandstoetter M, Tomic S, Pedrazzi S, Peruzzi A, Pajares G, Kaplanis G, Perez-Ruiz M, Valero C, del 
Cerro J, Vieri M, Rabatel G, Debilde B, 2017. Fleets of robots for environmentally-safe pest control in agriculture. Precis. Agric. 18:574-614.

Heap I. 2021. The international herbicide-resistant weed database. Available from: www.weedscience.org Accessed: 01 April 2021.

Hefner M, Gebremikael MT, Canali S, Sans Serra FX, Petersen KK, Sorensen JN, De Neve S, Labouriau R, Kristensen HL, 2020. Cover crop composition mediates the constraints and benefits of roller-crimping and incorporation in organic white cabbage production. Agric. Ecosyst. Environ. 296:106908.

Hillocks RJ, 2012. Farming with fewer pesticides: EU pesticide review and resulting changes for UK agriculture. Crop Prot. 31:85-93.

Jabran K, 2017. Brassicaceae allelopathy for weed control. In: K. Jabran (Ed.), Manipulation of allelopathic crops for weed control. Springer briefs in plant science. Springer International Publishing AG, Switzerland, pp. 21-27.

Jess S, Kildea S, Moody A, Rennick G, Murchie AK and Cooke LR, 2014. European Union policy on pesticides: implications for agriculture in Ireland. Pest Manag. Sci. 70:1646-54.

Jouini A, Verdeguer M, Pinton S, Araniti F, Palazzolo E, Badalucco L, Laudicina VA, 2020. Potential effects of essential oils extracted from Mediterranean aromatic plants on target weeds and soil microorganisms. Plants 9:1289.

Khan MJ, Brodie GI, Gupta D, Foletta S, 2018. Microwave soil treatment improves weed management in Australian dryland wheat. Trans. ASABE 61:671-80.

Kim DS, Kim S, Fennimore SA, 2021. Evaluation of broadcast steam application with mustard seed meal in fruiting strawberry. HortSci. 1(aop):1-6.

Korres NE, Burgos NR, Travlos I, Vurro M, Gitsopoulos TK, Varanasi VK, Duke SO, Kudsk P, Brabham C, Rouse CE, Salas-Perez R, 2019. New directions for integrated weed management: Modern technologies, tools and knowledge discovery. Adv. Agron 155:243-319).

Kraehmer H, Van Almsick A, Beffa R, Dietrich H, Eckes P, Hacker E, Hain R, John Strek H, Stuebler H, Willms L, 2014. Herbicides as weed control agents: state of the art: II. Recent achievements. Plant Physiol. 166:1132-48.

Kunz C, Weber JF, Peteinatos GG, Sökefeld M, Gerhards R, 2018. Camera steered mechanical weed control in sugar beet, maize and soybean. Precis. Agric. 19:708-10.

Liebman M, Baraibar B, Buckley Y, Childs D, Christensen S, Cousens R, Eizenberg H, Heijting S, Loddo D, Merotto A Jr., Renton M, Riemens M, 2016. Ecologically sustainable weed management: How do we get from proof-of-concept to adoption? Ecol. Appl. 26:1352-69.

Loddo D, Scarabel L, Sattin M, Pederzoli A, Morsiani C, Canestrale R, Tommasini MG, 2020. Combination of herbicide band application and inter-row cultivation provides sustainable weed control in maize. Agronomy 10:20.

Lopez-Granados F, 2011. Weed detection for site-specific weed management: mapping and real-time approaches. Weed Res. 51:1-11.

Loureiro I, Escorial C, Hernández Plaza E, González Andújar JL, Chueca MC, 2017. Current status in herbicide resistance in Lolium rigidum in winter cereal fields in Spain: evolution of resistance 12 years after. Crop Prot. 102:10-8.

Main DC, Sanderson KR, Fillmore SAE, Ivany JA, 2013. Comparison of synthetic and organic herbicides applied banded for weed control in carrots (Daucus carota L.). Can. J. Plant Sci. 93:857-61.
Matteo R, Back MA, Reade JPH, Ugolini L, Pagnotta E, Lazzeri L, 2018. Effectiveness of defatted seed meals from Brassicaceae with or without crude glycerin against black grass (Alopecurus myosuroides Huds.). Ind. Crops Prod. 111:506-12.

McElroy JS, 2014. Vavilovian mimicry: Nikolai Vavilov and his little-known impact on weed science. Weed Sci. 62:207-16.

Mortensen DA, Egan JF, Maxwell BD, Ryan MR, Smith RG, 2012. Navigating a critical juncture for sustainable weed management. BioSci. 62:75-84.

Navarro-Miró D, Blanco-Moreno JM, Ciaccia C, Chamorro L, Testani E, Kristensen HL, Hefner M, Tamm K, Bender I, Jakop M, Bavec M, Védie H, Lepse L, Canali S, Sans FX, 2019. Agroecological service crops managed with roller crimper reduce weed density and weed species richness in organic vegetable systems across Europe. Agron. Sustain. Dev. 39:55.

Nelson DS, Bullock GC, 2003. Simulating a relative environmental effect of glyphosate-resistant soybeans. Ecol. Econ. 45:189202.

Pannacci E, Tei F, 2014. Effects of mechanical and chemical methods on weed control, weed seed rain and crop yield in maize, sunflower and soyabean. Crop Prot. 64:51-9.

Peruzzi A, Martelloni L, Frasconi C, Fontanelli M, Pirchio M, Raffaelli M, 2017. Machines for non-chemical intra-row weed control in narrow and wide-row crops: a review. J. Agric. Eng. XLVIII:583.

Perez-Ruiz M, Carballido J, Agüera J, Rodríguez-Lizana A, 2013. Development and evaluation of a combined cultivator and band sprayer with a row-centering RTK-GPS guidance system. Sensors 13:3313-30.

Peters B, Strek HJ, 2008. Herbicide discovery in light of rapidly spreading resistance and ever-increasing regulatory hurdles. Pest Manag. Sci. 74:2211-5.

Pouresmaeil M, Nojadeh MS, Movafeghi A, Maggi F, 2020. Exploring the bio-control efficacy of Artemisia fragrans essential oil on the perennial weed convolvulus arvensis: inhibitory effects on the photosynthetic machinery and induction of oxidative stress. Ind. Crops Prod. 155:112785.

Rajković M, Malidža G, Tomaš Simin M, Milić D, Glavaš-Trbić D, Meseldžija M, Vrbničanin S, 2021. Sustainable organic corn production with the use of flame weeding as the most sustainable economical solution. Sustainability 13:572.

Ranaldo M, Carlesi S, Costanzo A, Bàrberi P, 2020. Functional diversity of cover crop mixtures enhances biomass yield and weed suppression in a Mediterranean agroecosystem. Weed Res. 60:96-108.

Scarabel L, Panozzo S, Loddo D, Mathiassen SK, Kristensen M, Kudsk P, Gitsopoulos T, Travlos I, Tani E, Chachalis D, Sattin M, 2020. Diversified resistance mechanisms in multi-resistant Lolium spp. in three European Countries. Front. Plant Sci. 11:608845.

Shaaban HAE, El-Ghorab AH, Shibamoto T, 2012. Bioactivity of essential oils and their volatile aroma components: review. J. Essent. Oil Res. 24: 203-212

Shergill LS, Schwartz-Lazaro LM, Leon R, Ackroyd VJ, Flessner ML, Bagavathiannan M, Everman W, Norsworthy JK, VanGessel MJ, Mirsky SB, 2020. Current outlook and future research needs for harvest weed seed control in North American cropping systems. Pest Manag. Sci. 76:3887-95.

Silvestri N, Grossi N, Mariotti M, Arduini I, Guglielminetti L, Raffaelli M, Cardelli R, 2021. Cover crop introduction in a Mediterranean maize cropping system. Effects on soil variables and yield. Agronomy 11:549. 
Spaeth M, Machleb J, Peteinatos GG, Saile M, Gerhards R, 2020. Smart harrowing-adjusting the treatment intensity based on machine vision to achieve a uniform weed control selectivity under heterogeneous field conditions. Agronomy 10:1925.

Steward BL, Gai J, Tang L, 2019. The use of agricultural robots in weed management and control. In: J. Billingsley (Ed.), Robotics and automation for improving agriculture. Vol. 44: Burleigh Dodds series in agricultural science. Burleigh Dodds Science Publishing, Cambridge, UK.

Taban A, Saharkhiz MJ, Naderi R, 2020. A natural post-emergence herbicide based on essential oil encapsulation by cross-linked biopolymers: characterization and herbicidal activity. Environ. Sci. Pollut. Res. 27:45844-58.

Torra J, Montull JM, Taberner A, Onkokesung N, Boonham N, Edwards R, 2021. Target-site and non-target-site resistance mechanisms confer multiple and cross-resistance to ALS and ACCase inhibiting herbicides in Lolium rigidum from Spain. Front. Plant Sci. 12:625138.

Umetsu N, Shirai Y, 2020. Development of novel pesticides in the 21st century. J. Pestic. Sci. 45:54-74.

United States Environmental Protection Agency (USEPA), 2021.
Risk assessment. Available from: https:/www.epa.gov/risk Last accessed: 17 February 2021.

Vasileiadis VP, van Dijk W, Verschwele A, Holb IJ, Vámos A, Urek G, Leskovšek R, Furlan L, Sattin M, 2016. Farm-scale evaluation of herbicide band application integrated with inter-row mechanical weeding for maize production in four European regions. Weed Res. 56:313-22.

Miguel-Rojas C, Pérez-de-Luque A, 2019. Safe nanotechnologies for increasing the effectiveness of environmentally friendly natural agrochemicals. Pest Manag. Sci. 75:2403-12.

Walsh MJ, Broster JC, Schwartz-Lazaro LM, Norsworthy JK, Davis AS, Tidemann BD, Beckie HJ, Lyon DJ, Soni N, Neve P, Bagavathiannan MV, 2018. Opportunities and challenges for harvest weed seed control in global cropping systems. Pest Manag. Sci. 74:2235-45.

Wilson RG, Young BG, Matthews JL, Weller SC, Johnson WG, Jordan DL, Owen MDK, Dixon PM, Shaw DR, 2011. Benchmark study on glyphosate resistant cropping systems in the United States. Part 4: weed management practices and effect on weed populations and soil seedbanks. Pest Manag. Sci. 67:771-80. 